\title{
Structural Change Detection in a Disturbed Conifer Forest Using a Geometric Optical Reflectance Model in Multiple-Forward Mode
}

\author{
Derek R. Peddle, Member, IEEE, Steven E. Franklin, Ryan L. Johnson, Mike B. Lavigne, and Mike A. Wulder
}

\begin{abstract}
Geometric optical reflectance models provide a physical linkage between image data and forest structure. We developed a "Multiple-Forward-Mode" pseudoinversion modeling approach to produce structural lookup tables for Landsat Thematic Mapper images before and after 1993 partial harvests in New Brunswick Canada. Modeling results validated for stand density, crown radius, and stem counts enabled simple forest structural change detection.
\end{abstract}

Index Terms-Canopy reflectance models, change detection, forest structure.

\section{INTRODUCTION}

A key information need in sustainable forest management is the amount of structural change in forest stands [1]. Change can result from a number of processes, including natural disturbances caused by fire, insects, and various human activities such as partial harvesting or silvicultural treatments [2], [3]. Much work in forest change detection using remote sensing has focussed on providing either a statistical indication of change in spectral response [4] or a spatial description of changes in landcover patterns [5], as reviewed in [6]. A quantitative physically based capability is highly desirable to augment such image differencing and classification methods. Ideally, forest structural information could be extracted from multidate imagery using geometric-optical canopy reflectance models [7] that predict reflectance caused by forest stand change. In this letter, we present a new multiple-forward-mode (MFM) pseudoinversion approach to using forest geometric-optical canopy reflectance models for detecting and quantifying forest structural change, and illustrate the approach with an example application in the Fundy Model Forest in eastern Canada.

Manuscript received September 28, 2001; revised December 12, 2001. This work was supported by the Fundy Model Forest and Fundy National Park, the Natural Sciences and Engineering Research Council of Canada (grants to D. R. Peddle and S. E. Franklin), the Alberta Research Excellence Program (grant to D. R. Peddle), and the NETERA/Multimedia Advanced Computational Infrastructure (University of Lethbridge).

D. R. Peddle is with the Department of Geography, University of Lethbridge, Lethbridge, AB, T1K 3M4, Canada (e-mail: derek.peddle@uleth.ca).

S. E. Franklin is with the Department of Geography, University of Calgary, Calgary, AB, T2N IN4, Canada (e-mail: franklin@ucalgary.ca).

R. L. Johnson was with the Department of Geography, University of Lethbridge, Lethbridge, AB, T1K 3M4, Canada. He is now with Iunctus Geomatics Corporation, Lethbridge, AB, TIJ 2B4, Canada (e-mail:ryan@terraengine.com).

M. B. Lavigne is with the Atlantic Forestry Centre, Canadian Forest Service, Fredericton, NB, E3B 5P7, Canada (e-mail: mlavigne@NRCan.gc.ca).

M. A. Wulder is with the Pacific Forestry Centre, Canadian Forest Service, Victoria, BC, V8Z IM5, Canada (e-mail: mwulder@PFC.Forestry.CA).

Digital Object Identifier 10.1109/TGRS.2002.807756

\section{REFleCtANCE Modeling}

\section{A. Geometric Optical Reflectance Models}

Geometric optical reflectance models provide a powerful basis for understanding the interactions of solar radiation with forest stands as a function of the physical dimensions and structure of forest canopies [8]. These reflectance models characterize forest stands as being comprised of the canopy, their shadows, and background forest floor material [9]. The spectral properties of these individual components (or endmembers) are required inputs to these models [10]. The objects (modeled trees) are described in terms of characteristic shapes and defined spatial dimensions and crown geometry [11]. These objects and the set of spectral component properties are distributed over an area equivalent to the instantaneous field of view (IFOV) of an airborne or satellite sensor (i.e., pixel spatial resolution). Within the IFOV, different magnitudes of tree densities and spatial patterns of trees can be modeled. A full range of solar illumination and sensor view angles can be simulated, while terrain variations such as different slopes and aspects can also be accounted for [12].

\section{B. Forward and Inverse Modeling}

In general, these models can be used in either forward or inverse mode [8]. In standard forward mode, pixel reflectance values are output in each spectral band, together with a set of scene fractions (percent sunlit canopy, percent sunlit background, and percent shadow within individual pixels), based on inputs of tree dimensions and stand density. In inversion mode, image pixel values are input to the model, with physical stand attributes output. For physical-structural analyses, model inversion is desirable; however, this can be complex with sometimes nonexact or no solutions, as well as being computationally intense. Further, some of the more sophisticated models are not invertible, due to their complexity (e.g., 5-Scale [13]).

\section{C. $M F M$}

To address this, we developed a different approach to running these models in MFM. In MFM, the requirement for specific physical dimension and form inputs is relaxed, since only a range of values is required. For example, instead of specifying exact values for crown radius and tree height (which may be impractical or unavailable), the user need only specify a range of values and a model increment. These ranges are easily provided for a given area or region from baseline inventories, field 
data, or published literature. Alternatively, broader ranges can be specified or theoretical minima and maxima used such that the approach is not constrained to require information specific to a given location or area. The model is then run multiple times in forward mode for each possible combination of physical canopy descriptors where, for a given physical input, all values are considered throughout the range with respect to a specified increment step. MFM runs execute rapidly and produce a set of output reflectance values stored in a lookup table (MFM-LUT). For a given MFM model run, the structural parameters used to produce each reflectance value are retained in the MFM-LUT. For each satellite pixel reflectance value from the digital image, the MFM-LUT is searched to identify matching reflectance values as generated by the model. If there are no matches, a thresholded proximity rule is used in spectral space, while any multiple matches are resolved using simple measures of central tendency that may optionally be further constrained with respect to computed scene fractions. The forest structure parameters from the model that are associated with the matched reflectance values constitute the forest structural output of interest. Using this MFM approach, a pseudoinversion modeling capability is achieved without explicit model inversion, which is particularly appealing for noninvertible models.

\section{EXAMPLE APPLICATION}

\section{A. Study Area and Dataset}

The study area is located in the Fundy Model Forest, on the north shore of the Bay of Fundy, New Brunswick, Canada. This is an active forest management area of coniferous, deciduous, and mixed-wood forest stands set within the Acadian Forest Region [14]. Based on available inventory data, field observations, and spectral data, areas of partially harvested stands within 150 ha of red spruce dominant forest were identified for study. All partial harvesting in these areas was performed in 1993, in which one third of the basal area was removed using mechanical harvest machinery.

Two Landsat Thematic Mapper (TM) images were acquired August 7, 1992 (preharvest) and September 6, 1997 (postharvest) over the study area. An atmospheric correction was applied to both images to derive surface reflectance values, and the images were coregistered and geometrically corrected to a reference UTM grid. Field spectral measurements [15] of forest component endmembers were obtained from a field spectroradiometer with reference to simultaneous irradiance spectra of a calibration panel to facilitate reflectance processing [16] for use with the satellite and modeled reflectance values.

\section{B. MFM Modeling}

The MFM approach is suitable for any canopy reflectance model, and runs using two separate interface modules. In this work, the Li-Strahler [12] geometric optical mutual shadowing (GOMS) model was used, since its ellipsoid representation of tree crowns has been shown in previous work [11] to be superior to other crown geometrical forms such as cylinders and cones [8]-[10], [17]. The GOMS model also deals with complex crown shadowing over broad stand density gradients and at higher solar zenith angles that characterize northern forests,

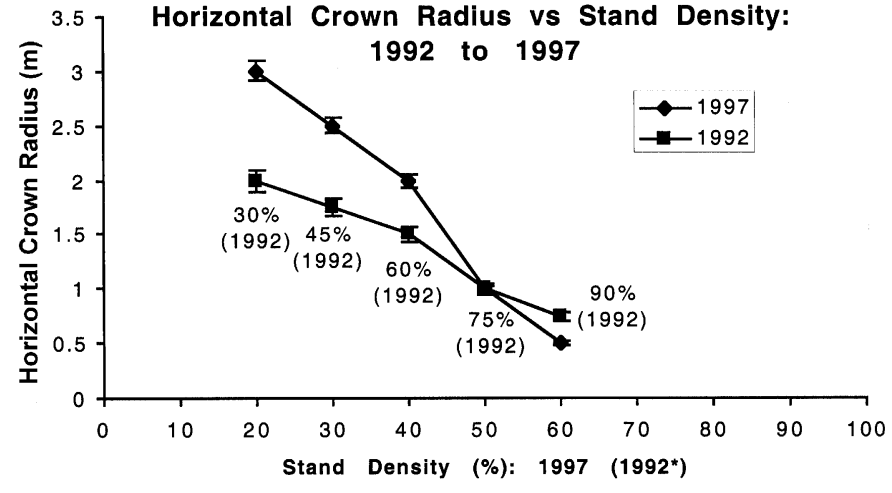

Fig. 1. MFM modeled 1992 and 1997 stand densities $(D)$ and horizontal crown radii $(r)$ that produced reflectance values matching Landsat TM data (*1992 preharvest $D$ values plotted with corresponding 1997 postharvest $D$ values according to one-third rate of thinning applied). Vertical bars indicate range of $r$ at each $D$ value.

as well as being suitable for coupled, regional scale classification and biophysical estimation algorithms [18]-[20].

A set of MFM input ranges was selected to parameterize the GOMS model with reference to knowledge of the area and geographical information system (GIS) forest inventory data. Software was written to control multiple runs of the reflectance model in MFM mode for each possible combination of all model inputs. The area has generally flat or gently sloping terrain; therefore, a slope value of $0^{\circ}$ was used in all model runs. The solar zenith (SZA) and azimuth (Az) angles corresponded to the solar position at the time of each Landsat TM image

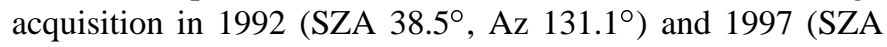
$44.3^{\circ}, \mathrm{Az} 144.8^{\circ}$ ). Since the solar positions were different, separate MFM-LUTs were generated for each satellite image date. Matches of reflectance values between each image and corresponding MFM-LUT were then derived for 1992 and 1997.

Since it is known that stand density and horizontal crown dimension are key controlling factors that influence forest stand reflectance [21], these parameters were analyzed in detail. The MFM-GOMS model inputs for stand density $(D)$ were varied from $0 \%$ to $100 \%$ in $10 \%$ intervals, while horizontal crown radius $(r)$ was varied from $r=0.5-3.0 \mathrm{~m}$ according to the GIS forest inventory. The remaining structural model inputs deal with vertical tree dimensions such as vertical crown radius, height to center of crown, and height distribution, all of which have much less influence on forest reflectance [21]. This was confirmed by a series of model runs in which each was systematically varied and the resulting reflectances evaluated over a range of stand densities. Accordingly, vertical tree dimensions were held constant to facilitate direct study of the stand density and horizontal crown dimension parameters of interest.

\section{RESULTS}

\section{A. Stand Density and Crown Dimension Estimates}

Horizontal crown radii $(r)$ were plotted against stand density $(D)$ for MFM-GOMS model reflectance values that matched the Landsat reflectances of the red spruce stands (Fig. 1) for the preharvest and postharvest TM images. For 1992, matches occurred at stand densities between $30 \%$ and $90 \%$, with modeled 
crown radii decreasing from $r=2.00-0.75$ mwith increasing stand density. For 1997, modeled and TM reflectance matches occurred at a different range of stand densities ( $D=20 \%$ to $60 \%)$ and horizontal crown radii $(r=3.00-0.50 \mathrm{~m})$ compared to 1992 , owing to the partial harvesting performed in the intervening years. For both years, the variability of $r$ decreased with increasing stand density.

From the partial harvest, it is known that these forest stands were subjected to a one-third thinning in stand density between the 1992 and 1997 TM image dates. However, the horizontal crown radii of the remaining unharvested trees in 1997 were virtually unchanged from 1992 for these even-aged red spruce stands, since five years of growth produced only a very small increase in horizontal crown dimension across a given mature stand (a small growth adjustment factor was applied to model results to account for this, based on projected vertical growth). This provided a basis to derive the final modeled stand density estimates for both years by comparing horizontal crown radius results at a given 1992 stand density to those obtained in 1997 at the stand density corresponding to the known rate of one-third thinning. For example, the modeled result for $r$ at $D=45 \%$ in 1992 would be compared to the $r$ value at $D=30 \%$ in 1997: if the $r$ values were unequal, this set of results was eliminated from the pool of potential structural values. The result of this analysis is shown in Fig. 1, in which 1992 stand densities are plotted on the $x$ axis with their correspondingly reduced (thinned) 1997 stand density values. The only point of intersection of modeled horizontal crown radii occurs at $r=1.10 \mathrm{~m}$ at a modeled preharvest stand density of 75\% (1992) and postharvest (1997) stand density of 50\%. At all other stand densities, the modeled $r$ values were different for each date and therefore violated the known equivalency of horizontal crown radii for trees from 1992 to 1997 . Accordingly, the MFM-GOMS model results were determined for 1992 and 1997 as $75 \%$ and 50\% stand density, respectively, with a horizontal crown radius of $r=1.10 \mathrm{~m}$.

In terms of validation, it is known from the Fundy Model Forest GIS forest inventory that the range of red spruce stand densities in this area was 30\% to $50 \%$ in 1997, and $45 \%$ to $75 \%$ in 1992. The modeling results of $D=50 \%$ (1997) and $75 \%$ (1992) were consistent with the higher end of these forest inventory ranges. The horizontal crown radius results were validated with respect to allometric equations that related 1992 inventory tree heights to crown width, yielding a horizontal crown radius of $0.96 \mathrm{~m}$, for which our modeled result of $r=1.10 \mathrm{~m}$ was in good agreement.

\section{B. Stem Count Estimates}

The stand density and horizontal crown radius estimates for 1992 and 1997 were used to derive estimates of stem counts from the preharvest and postharvest satellite imagery. This was done by first calculating the total area of trees $(\alpha)$ in a pixel as a function of modeled stand density $(D)$ and the pixel size ( $\sigma=900 \mathrm{~m}^{2}$ for $30-\mathrm{m}$ Landsat TM pixels) as

$$
\alpha=\frac{D}{100} \sigma
$$

and then deriving a stem count estimate $(\beta)$ for pixels, subsequently converted to hectares, as a function of $\alpha$ and individual
TABLE I

Summary of MAJOR RESUlts AND CHANGE IN STRUCTURAL PARAMETER ESTIMATES BETWEEN 1992 AND 1997, WITH ASSOCIATED INDEPENDENT FIELD INVENTORY VALIDATION DATA

\begin{tabular}{l|c|c|c}
\hline Structural Parameter & 1992 & 1997 & $\Delta$ \\
\hline Field: Stand Density & $45 \%-75 \%$ & $30 \%-50 \%$ & \\
\hline MFM: Stand Density & $75 \%$ & $50 \%$ & $25 \%$ \\
\hline Field: Stem count & 1800 stems/ha & 1200 stems/ha & 600 stems/ha \\
\hline MFM: Stem count ( $\beta)$ & 1995 stems/ha & 1249 stems/ha & 746 stems/ha \\
\hline
\end{tabular}

stem area $(\chi)$, where $\chi$ is computed as the area of the projected circle from the maximum horizontal axis dimension of the GOMS model ellipsoid with respect to the horizontal crown radius $(r)$ for adjacent nonoverlapping crowns, as

$$
\beta=\frac{\alpha}{\chi}=\frac{\alpha}{\pi r^{2}}
$$

Independent field-based stem counts for this area were estimated at 1800 stems/ha (1992) and 1200 stems/ha (1997), for which the modeled results (Table I) of 1995 stems/ha and 1249 stems/ha, respectively, were in good correspondence.

\section{Forest Structural Change Detection}

In Table I, a summary of all major results is provided, together with calculations of structural change from 1992 to 1997 from both the modeling results and the independent validation data. The overall modeled change in stand density was estimated to be a $25 \%$ reduction, which is within the range of inventory information. From field data, the partial harvesting produced a reduction of 600 stems/ha, while the model estimated 746 stems/ha reduction. This represents a significant result using regionalscale satellite imagery such as Landsat TM, since most previous stem count studies using optical remote sensing have required high spatial resolution airborne imagery for which direct crown delineation and stem counts were possible over limited areas.

\section{CONCLUSION}

By using a geometric optical reflectance model with an MFM lookup table approach, quantitative, physical information has been provided that relates satellite spectral response to forest structure. The inputs to the MFM approach are less stringent and easier to specify compared to standard forward or inverse mode methods. This is because only a range of input stand dimensions is required, instead of exact model inputs. MFM modeling results for 1992 and 1997 were, respectively, 75\% and 50\% stand density, and 1995 stems/ha and 1249 stems/ha, with forest structural change estimated as reductions of $25 \%$ stand density and 746 stems/ha due to forest partial harvesting, all of which were in good correspondence with independent forest inventory and field information. The MFM approach provides structural outputs similar to model inversion and is suitable for any canopy reflectance model including complex sophisticated models that are not otherwise invertible. 


\section{ACKNOWLEDGMENT}

The authors gratefully acknowledge A. Strahler and staff (Boston University), F. Hall and staff (NASA Goddard Space Flight Center), and W. Lucht (Potsdam Institute for Climate Impact Research) for provision and support of the canopy reflectance model used in this study.

\section{REFERENCES}

[1] T. A. Spies, "Forest stand structure, composition and function," in Creating a Forestry for the 21st Century: The Science of Ecosystem Management, K. A. Kohm and J. F. Franklin, Eds. Washington, DC: Island Press, 1997, pp. 11-30.

[2] H. Olsson, "Changes in satellite-measured reflectances caused by thinning cuttings in boreal forest," Remote Sens. Environ., vol. 50, pp. 221-230, 1994

[3] S. E. Franklin, M. B. Lavigne, L. M. Moskal, M. A. Wulder, and T. M. McCaffrey, "Interpretation of partial harvest forest conditions in New Brunswick using Landsat TM enhanced wetness difference imagery (EWDI)," Can. J. Remote Sens., vol. 27, pp. 118-128, 2001.

[4] T. Fung and E. LeDrew, "The determination of optimal thresholds for change detection using various accuracy indices," Photogramm. Eng. Remote Sens., vol. 54, pp. 1449-1454, 1988.

[5] W. Cohen, M. Fiorella, J. Gray, E. Helmer, and K. Anderson, "An efficient and accurate method for mapping forest clearcuts in the Pacific northwest using Landsat imagery," Photogramm. Eng. Remote Sens., vol. 64, pp. 293-300, 1998.

[6] P. Coppin and M. Bauer, "Digital change detection in forest ecosystems with remote sensing imagery," Remote Sens. Rev., vol. 13, pp. 207-234, 1996.

[7] D. L. B. Jupp and J. Walker, "Detecting structural growth changes in woodlands and forests: The challenge for remote sensing and the role of geometric-optical modeling," in The Use of Remote Sensing in the Modeling of Forest Productivity, H. L. Gholz, K. Nakane, and H. Shimoda, Eds. Dordrecht, The Netherlands: Kluwer, 1997, pp. 75-108.

[8] X. Li and A. H. Strahler, "Geometric-optical modeling of a conifer forest canopy," IEEE Trans. Geosci. Remote Sensing, vol. GE-23, pp. 705-720, Sept. 1985.
[9] F. G. Hall, Y. E. Shimabukuro, and K. F. Huemmrich, "Remote sensing of forest biophysical structure in boreal stands of picea mariana using mixture decomposition and geometric reflectance models," Ecolog. Appl., vol. 5, no. 4, pp. 993-1013, 1995.

[10] M. F. Jasinski and P. S. Eagleson, "The structure of red-infrared scattergrams of semivegetated landscapes," IEEE Trans. Geosci. Remote Sensing, vol. 27, pp. 441-451, July 1989.

[11] D. R. Peddle, F. G. Hall, and E. F. LeDrew, "Spectral mixture analysis and geometric optical reflectance modeling of boreal forest biophysical structure," Remote Sens. Environ., vol. 67, no. 3, pp. 288-297, 1999.

[12] X. Li and A. H. Strahler, "Geometric-optical bidirectional reflectance modeling of the discrete crown vegetation canopy: Effect of crown shape and mutual shadowing," IEEE Trans. Geosci. Remote Sensing, vol. 30, pp. 276-292, Mar. 1992.

[13] S. G. Leblanc and J. M. Chen, "A windows graphic user interface (GUI) for the five-scale model for fast BRDF simulations," Remote Sens. Rev., vol. 19, pp. 293-305, 2000.

[14] J. Rowe, "Forest regions of Canada," Environment Canada, Canadian Forest Service Publication, Ottawa, ON, Canada, 1300, 1972.

[15] J. Miller, P. White, J. Chen, D. Peddle, G. McDermid, R. Fournier, P. Shepherd, I. Rubinstein, J. Freemantle, R. Soffer, and E. LeDrew, "Seasonal change in understorey reflectance of boreal forests and influence on canopy vegetation indices," J. Geophys. Res., vol. 102, no. D24, pp. 29 475-29 482, 1997.

[16] D. R. Peddle, H. P. White, R. J. Soffer, J. R. Miller, and E. F. LeDrew, "Reflectance processing of remote sensing spectroradiometer data," Comput. Geosci., vol. 27, pp. 203-213, 2001.

[17] F. G. Hall, D. R. Peddle, and E. F. LeDrew, "Remote sensing of biophysical variables in boreal forest stands of picea mariana," Int. J. Remote Sens., vol. 17, no. 15, pp. 3077-3081, 1996.

[18] F. G. Hall, D. E. Knapp, and K. F. Huemmrich, "Physically based classification and satellite mapping of biophysical characteristics in the southern boreal forest," J. Geophys. Res., vol. 102, no. D24, pp. 29 567-29580, 1997.

[19] D. R. Peddle, F. G. Hall, E. F. LeDrew, and D. E. Knapp, "Classification of forest land cover in BOREAS. II: Comparison of results from a subpixel scale physical modeling approach and a training based method," Can. J. Remote Sens., vol. 23, no. 2, pp. 131-142, 1997.

[20] D. R. Peddle, "Integration of a geometric optical reflectance model with an evidential reasoning image classifier for improved forest information extraction," Can. J. Remote Sens., vol. 25, no. 2, pp. 189-196, 1999.

[21] G. Guyot, D. Guyon, and D. G. Riom, "Factors affecting the spectral response of forest canopies: A review," Geocarto Int., vol. 3, pp. 3-18, 1989 